Copyright (C) 2021 University of Bucharest Printed in Romania. All rights reserved ISSN print: $1224-5984$

ISSN online: 2248-3942
Rom Biotechnol Lett. 2021; 26(4): 2800-2807

doi: $10.25083 / \mathrm{rbl} / 26.4 / 2800.2807$

Received for publication, July, 15, 2020

Accepted, November, 30, 2020

Original paper

\title{
Screening of local wild-type Xanthomonas spp. for xanthan biosynthesis using media with different carbon sources
}

\author{
IDA ZAHOVIĆ ${ }^{*}$, JELENA DODIĆ ${ }^{1}$, SINIŠA MARKOV ${ }^{\mathbf{1}}$, JOVANA GRAHOVAC ${ }^{1}$, \\ MILA GRAHOVAC ${ }^{2}$, ZORANA TRIVUNOVIĆ ${ }^{1}$
}

${ }^{1}$ University of Novi Sad, Faculty of Technology Novi Sad, Department of Biotechnology and Pharmaceutical Engineering, Novi Sad, Serbia

${ }^{2}$ University of Novi Sad, Faculty of Agriculture, Department of Phytomedicine and Environmental Protection, Novi Sad, Serbia

\begin{abstract}
In this study the screening of different Xanthomonas strains, isolated from infected crucifers and pepper leaves, for xanthan biosynthesis on semi-synthetic media containing different carbon sources was performed. The success of xanthan biosynthesis was estimated based on xanthan concentration in media and its molecular weight. Glucose and glycerol were investigated as carbon sources in a quantity of $20.0 \mathrm{~g} / \mathrm{L}$. Xanthan biosynthesis by different Xanthomonas isolates on two different cultivation media was carried out in Erlenmeyer flasks under aerobic conditions for $168 \mathrm{~h}$. According to the obtained results selection of the carbon source, producing strain and their combination have a statistically significant effect on xanthan quantity and quality. The results obtained in this study indicate that local wild-type Xanthomonas strains isolated from pepper leaves have a great potential for application in biotechnological production of good-quality xanthan on glycerol-based media.
\end{abstract}

Keywords Biotechnological production, bacterial biopolymer, Xanthomonas isolates, medium composition, biopolymer molecular weight.

To cite this article: ZAHOVIĆ I, DODIĆ J, MARKOV S, GRAHOVAC J, GRAHOVAC M, TRIVUNOVIĆ Z. Screening of local wild-type Xanthomonas spp. for xanthan biosynthesis using media with different carbon sources. Rom Biotechnol Lett. 2021; 26(4): 2800-2807. DOI: $10.25083 / \mathrm{rbl} / 26.4 / 2800-2807$

*Corresponding author: IDA ZAHOVIĆ, University of Novi Sad, Faculty of Technology Novi Sad, Department of Biotechnology and Pharmaceutical Engineering, Bd cara Lazara 1, 21102, Novi Sad Novi Sad, Serbia

E-mail: ida.zahovic@uns.ac.rs 


\section{Introduction}

Xanthan is one of the most important non-toxic and biodegradable polysaccharide of microbial origin (GARCÍA-OCHOA \& al [1]). Outstanding rheological characteristics make xanthan suitable for application in various branches of industries, such as food and foodpackaging, pharmaceutical, cosmetic, paint, chemical, petroleum, textile and others (DEMIRCI \& al [2]; KASSIM [3]). Xanthan is produced by many types of bacteria of the genus Xanthomonas but $X$. campestris is the most widely used for the industrial production of xanthan (GUMUS \& al [4]). It is known that glucose and sucrose are the most commonly used carbon sources in cultivation media (GARCÍA-OCHOA \& al [1]). However, the rise in prices and the increasing demands for these sugars indicate the need for utilization of alternative substrates of lower market value (DEMIRCI \& al [2]). The waste streams and by-products from food and beverage industry which contain glucose and sucrose may be suitable as alternative substrates for xanthan production, but their use is limited primarily by competitiveness on the market (RONČEVIĆ \& al [5]; GHASHGHAEI \& al [6]) and by their availability, which is restricted to the territories where the technological processes in which they originate are performed and/or generation season (RONČEVIĆ \& al [7]). Data from available scientific and professional literature indicate that certain strains of bacteria of the genus Xanthomonas possess the ability to synthesize xanthan on a medium with glycerol as the sole carbon source (REIS \& al [8]; TRINDADE \& al [9]). Research related to the development of a biotechnological process of the production of xanthan on glycerol is still in initial stages, probably due to impaired metabolic activity of the applied production microorganism (WANG \& al [10]). Considering all aforementioned, there is a need for isolation of new strains able to metabolize glycerol and produce xanthan, as well as to optimize the process of production, with the aim of achieving the highest efficiency of bioprocess.

The aim of this study was screening of reference strain X. campestris ATCC 13951 and Xanthomonas strains isolated from different vegetable cultures for xanthan production on semi-synthetic media containing glucose and glycerol as carbon source. The bioprocess success was estimated based on xanthan concentration in media and biopolymer molecular weight.

\section{Materials and Methods}

\section{Producing microorganisms}

The reference strain X. campestris ATCC 13951, eight Xanthomonas strains isolated from crucifers (Am, $\mathrm{CF}, \mathrm{CB}, \mathrm{KA}, \mathrm{Xp} 3-1, \mathrm{Xp} 7-2, \mathrm{Mn} 7-2,12-2$ ) and five Xanthomonas strains isolated from pepper leaves (PL1, PL2, PL3, PL4, PL5) were used as the producing microorganisms in these experiments. All strains were stored at $4{ }^{\circ} \mathrm{C}$ on agar slant (Yeast Maltose Agar, HiMedia,
India) and subcultured every four weeks. Strains CF, CB, $\mathrm{KA}, \mathrm{Xp}$ 3-1, Xp 7-2, Am, Mn 7-2 and 12-2 were isolated from infected crucifers and stored in the Microbial Culture Collection of the Faculty of Technology Novi Sad, Serbia and strains PL1, PL2, PL3, PL4 and PL5 were isolated from infected pepper leaves and stored in the Microbial Culture Collection of the Faculty of Agriculture in Novi Sad.

\section{Cultivation media}

The commercial medium (Yeast Maltose Broth, HiMedia, India) was used for inoculum preparation, while xanthan production was performed on semi-synthetic media with two different carbon sources. Glucose and commercial glycerol (HiMedia, India) were investigated as sources of this nutrient and used in a quantity of $20.0 \mathrm{~g} / \mathrm{L}$. The cultivation media also contained yeast extract $(3.0 \mathrm{~g} / \mathrm{L}),\left(\mathrm{NH}_{4}\right)_{2} \mathrm{SO}_{4}(1.5 \mathrm{~g} / \mathrm{L}), \mathrm{K}_{2} \mathrm{HPO}_{4}(3.0 \mathrm{~g} / \mathrm{L})$ and $\mathrm{MgSO}_{4} \cdot 7 \mathrm{H}_{2} \mathrm{O}(0.3 \mathrm{~g} / \mathrm{L})$. The $\mathrm{pH}$ value of all used media was adjusted to $7.0 \pm 0.2$ and then sterilized by autoclaving $\left(121^{\circ} \mathrm{C}, 2.1 \mathrm{bar}, 20 \mathrm{~min}\right)$.

\section{Inoculum preparation}

Xanthomonas strains were subcultured on agar slant and incubated at $25^{\circ} \mathrm{C}$ for $48 \mathrm{~h}$. Further, inoculum preparation procedure was included suspending of producing microorganism cells in Yeast Maltose Broth. The prepared suspension was then incubated in aerobic conditions at $25^{\circ} \mathrm{C}$ and $150 \mathrm{rpm}$ (laboratory shaker $\mathrm{KS}$ $4000 \mathrm{i}$ control, Ika ${ }^{\circledR}$ Werke, Germany) for $48 \mathrm{~h}$.

\section{Xanthan production}

The xanthan production was carried out in $300 \mathrm{~mL}$ Erlenmeyer flasks with $100 \mathrm{~mL}$ of the cultivation medium with the appropriate composition. Inoculation was performed by adding $10 \%$ (v/v) of inoculum prepared as previously described. The biosynthesis was performed under aerobic conditions at $30^{\circ} \mathrm{C}$ and $150 \mathrm{rpm}$ (laboratory shaker KS 4000i control, Ika ${ }^{\circledR}$ Werke, Germany) for $168 \mathrm{~h}$.

\section{Xanthan separation}

At the end of biosynthesis, the xanthan was separated from the supernatant of cultivation medium by precipitation with cold $96 \%$ (v/v) ethanol, as described in previous research (RONČEVIĆ \& al [5]).

\section{Determination of xanthan molecular weight}

The average molecular weight of the separated xanthan was estimated based on the intrinsic viscosity of its solution in $0.1 \mathrm{M}$ sodium chloride using the MarkHouwink type equation (MILAS \& al [11]).

\section{Data analysis}

All experiments were carried out in triplicate and the results were averaged. The experimental data were processed by analysis of variance (Two-Way ANOVA) at the significance level of $\alpha=0.05$ using Statistica 13.2 software (Dell Inc., USA). 


\section{Results and Discussion}

\section{Statistical analysis of experimental results}

In order to examine the effect of different Xanthomonas strains and carbon sources on xanthan production, statistical analysis of experimental data was carried out. The summary results of Two-Way ANOVA analysis for xanthan concentration in media and xanthan molecular weight are given in Table 1 and Table 2, respectively.

Table 1. Two-Way ANOVA results for the effect of different Xanthomonas strains and carbon sources on xanthan concentration in media

\begin{tabular}{ccccccc}
\hline Xanthomonas strain & Variability & SS & DF & MS & F-value & $\boldsymbol{p}$-value \\
\hline \multirow{2}{*}{$\begin{array}{c}\text { Isolates from } \\
\text { crucifers }\end{array}$} & Strain & 189.510 & 8 & 23.689 & 119.020 & $<0.000001$ \\
& Carbon source & 64.587 & 1 & 64.587 & 324.490 & $<0.000001$ \\
& Strain and carbon source & 153.670 & 8 & 19.209 & 96.510 & $<0.000001$ \\
& Error & 7.165 & 36 & 0.199 & - & - \\
\hline \multirow{2}{*}{$\begin{array}{c}\text { Isolates from } \\
\text { pepper leaves }\end{array}$} & Strain & 17.399 & 4 & 4.350 & 22.245 & $<0.000001$ \\
& Carbon source & 85.629 & 1 & 85.629 & 437.931 & $<0.000001$ \\
& Strain and carbon source & 11.820 & 4 & 2.955 & 15.113 & $<0.000001$ \\
& Error & 3.911 & 20 & 0.196 & - & - \\
\hline
\end{tabular}

$\mathrm{SS}$ - sum of squares; DF - degrees of freedom; MS - mean square

The results presented in Table 1 show that the $\mathrm{p}$-values for the analyzed parameters and their interaction are much lower than 0.05 , which indicates that all applied Xanthomonas strains and carbon sources as well as their combination have a statistically significant effect on xanthan concentration in cultivation media. This is in agreement with results from research where different xanthan yield was obtained when various carbon sources such as glucose, galactose, sucrose, maltose and lactose were used for xanthan production by $X$. campestris isolated from soil (KUMARA \& al [12]), and other research where xanthan yield varied when eighteen different strains of $X$. campestris pv. pruni isolated from plum, peach or tangerine leaves were cultivated on sucrose containing medium (MOREIRA \& al [13]). However, if attention is paid to the mean square values presented in the same table, it can be concluded that the carbon source has a much greater effect on both groups of results for xanthan concentration in media, while the effect of Xanthomonas strains is considerably lower. Combination of Xanthomonas strains and carbon sources proved to have the lowest effect on xanthan production, due to the lowest mean square value for both group of results. This indicates that the composition of cultivation medium, i.e. selection of carbon source is of critical importance for this bioprocess efficacy. An explanation for this can be found in available literature where it is reported that different Xanthomonas species possess different metabolic pathways and cycles (BRENNER \& al [14]).

Table 2. Two-Way ANOVA results for the effect of different Xanthomonas strains and carbon sources on xanthan molecular weight

\begin{tabular}{ccccccc}
\hline Xanthomonas strains & Variability & SS & DF & MS & F-value & $\boldsymbol{p}$-value \\
\hline \multirow{4}{*}{$\begin{array}{c}\text { Isolates from } \\
\text { crucifers }\end{array}$} & Strains & $3.325 \cdot 10^{11}$ & 8 & $4.156 \cdot 10^{10}$ & 105.764 & $<0.000001$ \\
& Carbon sources & $1.244 \cdot 10^{11}$ & 1 & $1.244 \cdot 10^{11}$ & 316.596 & $<0.000001$ \\
& Strains and carbon sources & $3.032 \cdot 10^{11}$ & 8 & $3.790 \cdot 10^{10}$ & 96.467 & $<0.000001$ \\
& Error & $1.415 \cdot 10^{10}$ & 36 & $3.929 \cdot 10^{8}$ & & \\
\hline Isolates from & Strains & $5.325 \cdot 10^{11}$ & 4 & $1.331 \cdot 10^{11}$ & 343.330 & $<0.000001$ \\
pepper leaves & Carbon sources & $2.362 \cdot 10^{12}$ & 1 & $2.362 \cdot 10^{12}$ & 6090.530 & $<0.000001$ \\
& Strains and carbon sources & $4.611 \cdot 10^{11}$ & 4 & $1.153 \cdot 10^{11}$ & 297.320 & $<0.000001$ \\
& Error & $7.755 \cdot 10^{9}$ & 20 & $3.878 \cdot 10^{8}$ & &
\end{tabular}

$\mathrm{SS}$ - sum of squares; DF - degrees of freedom; MS - mean square 
The quality of xanthan depends of various factors such as the producing strain, the cultivation medium composition and the process conditions, and can be estimated based on several parameters, such as the viscosity of its solutions, the composition of the macromolecules, the molecular weight, etc. (BAJIĆ \& al [15]). Within this research, the quality of the produced biopolymer was estimated based on the average molecular weight. The results given in Table 2 show that the $p$-values for the analyzed parameters and their interaction are much lower than 0.05 , which indicates that the applied Xanthomonas strains and carbon sources as well as their combination have a statistically significant effect on the average molecular weight of xanthan. This is in accordance with results from research where light yellow mucoid colonies and small darker yellow mucoid colonies of $X$. campestris NRRL8-1459 produced biopolymer with structural differences on glucose containing media (CADMUS \& al [16]). If attention is paid to the mean square values presented in the same table, it can be concluded that the carbon source has a much greater effect on both groups of results, while the effect of Xanthomonas strains was also very high but lower than effect of carbon source. This indicates that the composition of cultivation medium, i.e. selection of carbon source is of great importance for xanthan quality. Despite the fact that genetic characteristics of Xanthomonas strains determinate chemical structure of produced xanthan (MOREIRA \& al [13]), its structure is also greatly affected by environmental conditions, which include the composition of cultivation medium, i.e. the carbon source selection and bioprocess parameters (GARCÍA-OCHOA $\&$ al [1]).

The results of the statistical analysis for xanthan concentration in media and xanthan molecular weight are also presented graphically with Box \& Whisker Plots in Figure 1-4.

\section{Effect of Xanthomonas strains and carbon source on xanthan concentration in media}

The results of statistical analysis of the effect of different Xanthomonas strains isolated from infected crucifers and pepper leaves on xanthan concentration in media at the end of biosynthesis are presented in Figure 1.
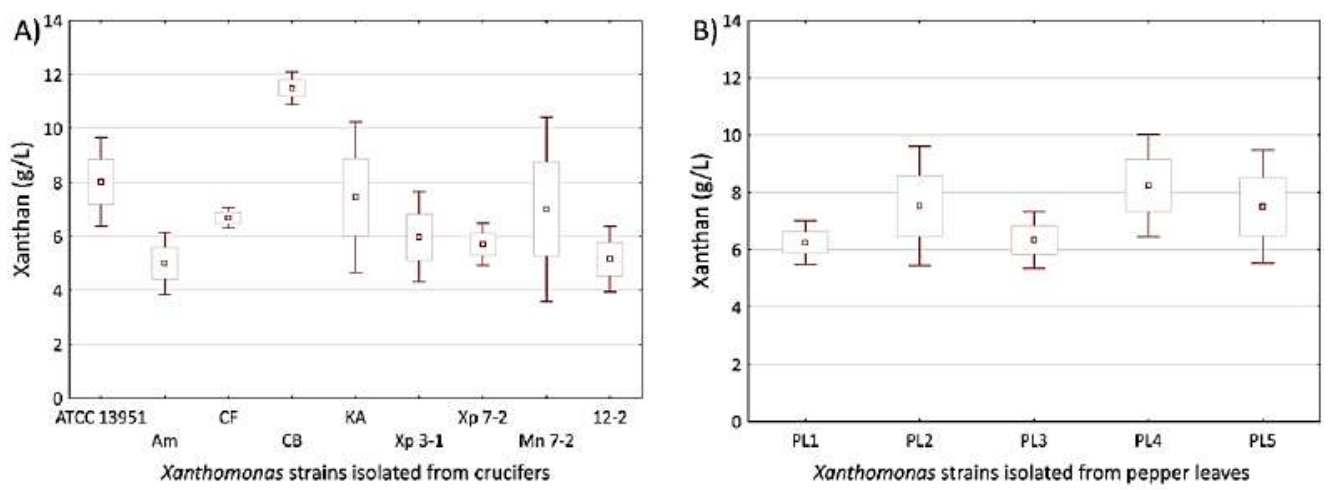

Figure 1. Effect of different Xanthomonas strains isolated from crucifers (A) and pepper leaves (B) on xanthan concentration in media.

Considering the results presented in Figure 1A, it can be noted that the $\mathrm{CB}$ isolate proved to be the best strain for xanthan production in applied experimental conditions for both used carbon sources. It can be noticed that, in addition to the reference strain, crucifers' isolates KA and Mn 7-2 showed good productivity, while other strains also produced xanthan, but in a significantly smaller amount. The obtained results of xanthan yield varied from around $4 \mathrm{~g} / \mathrm{L}$ to $12 \mathrm{~g} / \mathrm{L}$ and are much higher comparing to the results obtained in other research where the highest xanthan yield of $6.8 \mathrm{~g} / \mathrm{L}$ was obtained by $X$. campestris isolated from infected cabbage leaves (KASSIM [3]). Values of xanthan yield achieved in this study are in the similar range with results reported in research conducted in Brazil obtained by $X$. campestris strains collected from infected cauliflower, broccoli and cabbage (NITSCHKE \& RODRIGUES [17]).
Graphically presented results in Figure 1B indicate that the production of xanthan under the applied experimental conditions is possible on both media by all applied Xanthomonas strains isolated from pepper leaves. However, it can be observed that xanthan yield was significantly higher when cultivation was performed by PL2, PL4 and PL5 isolates. The results of xanthan yield obtained in this study were in range from around $6 \mathrm{~g} / \mathrm{L}$ to $10 \mathrm{~g} / \mathrm{L}$ and are in accordance with results conducted in Turkey were xanthan yield of $6.4 \mathrm{~g} / \mathrm{L}$ was achieved by $X$. axonopodis pv. vesicatoria strain isolated from pepper (GUMUS \& al [4]).

In Figure 2 the results of statistical analysis of the effect of different carbon sources on xanthan concentration in media obtained by cultivation of Xanthomonas strains isolated from crucifers and pepper leaves are presented. 
The results given in Figure $2 \mathrm{~A}$ show that higher xanthan concentration in media was achieved when bioprocesses were performed on glucose-based cultivation media. It can be noted that glucose is more suitable carbon source for xanthan biosynthesis when using Xanthomonas strains isolated from crucifers. This result is in accordance with findings from literature data where the highest xanthan yield was obtained by $X$. campestris GK6 strain isolated from infected cabbage leaves on media with glucose as a carbon source, among others (LEELA \& SHARMA, [18]). On the other side, from the results shown in Figure 2B it can be seen that glycerol is more preferred carbon source for xanthan biosynthesis when Xanthomonas strains isolated from pepper leaves are used.
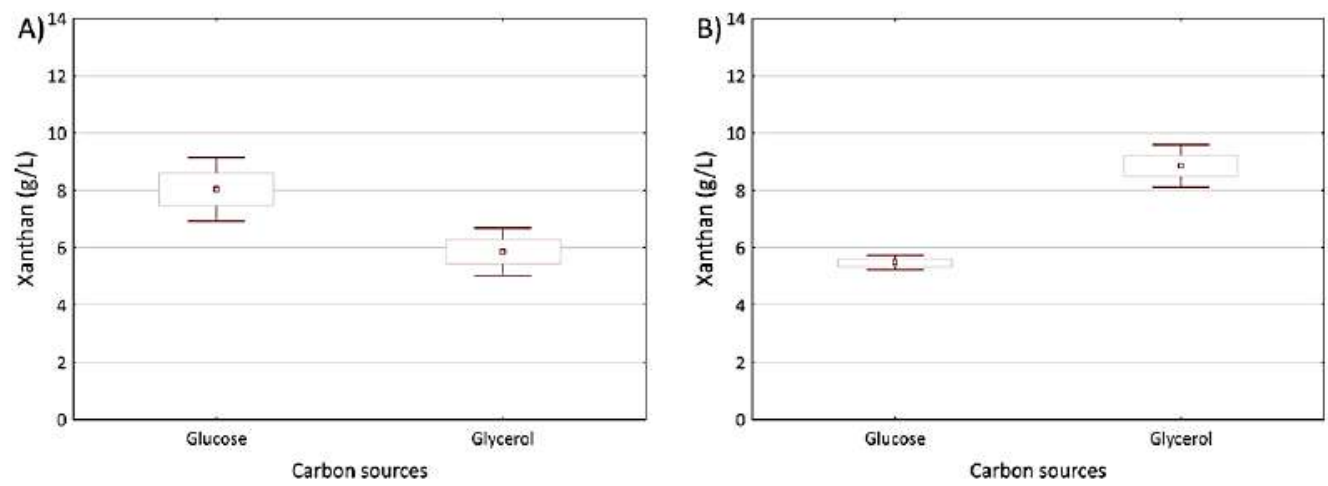

Figure 2. Effect of different carbon sources on xanthan concentration in media obtained by cultivation of Xanthomonas strains isolated from crucifers $(\mathbf{A})$ and pepper leaves $(\mathbf{B})$.

Summary, the results presented in Figure 2A and Figure 2B suggest that the best results for xanthan production by Xanthomonas strains isolated from crucifers were achieved when medium with glucose was used, while isolates from pepper leaves were the most productive on media with glycerol. This is in accordance with literature data where it is noted that nutrients need and biopolymer yield may be different among various strains (CADMUS $\&$ al [17]).

Afore mentioned results indicate that glycerol potentially may be suitable carbon source for industrial xanthan production by Xanthomonas strains isolated from pepper leaves. This opens the possibility for usage of crude glycerol, a major by-product of the biodiesel industry, as raw material in xanthan production. Since there has been a significant increase in the biodiesel production due to the growing demand for biofuels, it may be a suitable substrate for cost-effective xanthan production but there is still a need for further research and optimization in order to ensure that impurities from crude glycerol do not have negative effect on xanthan production (NWACHUKWU \& al [19]).

\section{Effect of Xanthomonas strains and carbon source on xanthan molecular weight}

The results of statistical analysis of the effect of different Xanthomonas strains isolated from crucifers and pepper leaves on xanthan molecular weight are presented in Figure 3.
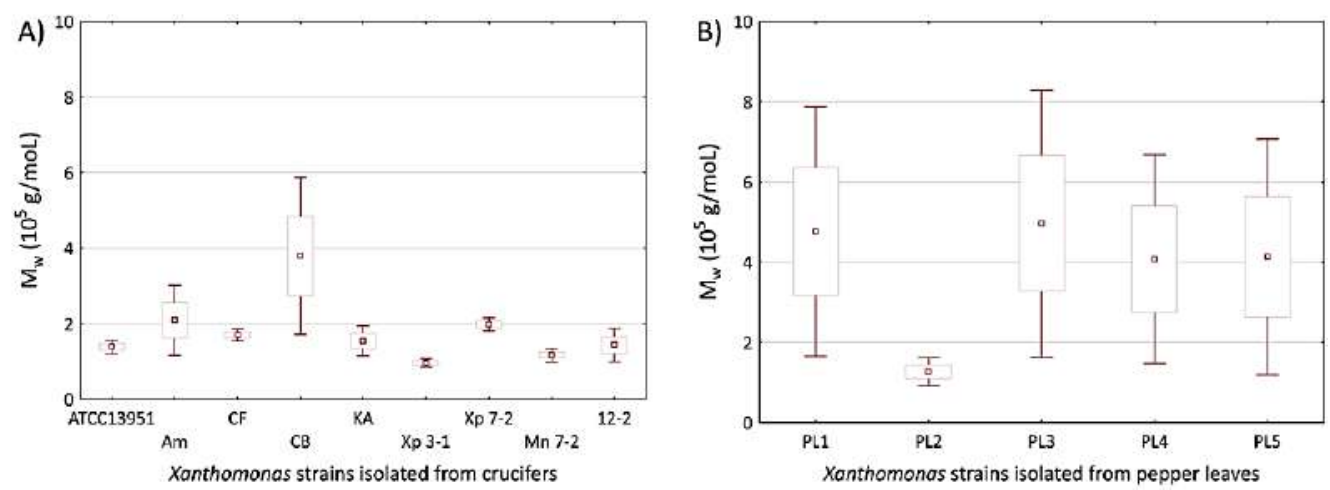

Figure 3. Effect of different Xanthomonas strains isolated from crucifers (A) and pepper leaves $(\mathbf{B})$ on xanthan molecular weight. 
Considering the mean value of molecular weight of xanthan produced by Xanthomonas strains isolated from crucifers for both carbon sources (Figure 3A), it can be noted that the biopolymer with the highest quality was achieved by cultivation of $\mathrm{CB}$ isolate. In addition, graphically presented results indicate that there is no statistically significant difference in the average molecular weight of xanthan when other crucifers' isolates were used. On the other hand, results obtained by analysis of xanthan separated from media after cultivation of Xanthomonas strains isolated from pepper leaves presented in Figure $3 \mathrm{~B}$ suggest that there is no statistically significant difference in biopolymer quality when PL1, PL3, PL4 and PL5 strains were applied. Among Xanthomonas strains isolated from pepper leaves, strain PL2 produces xanthan of the lowest quality regardless of which carbon source is added in cultivation medium.

Results presented in Figure 3A and Figure 3B suggest that regardless to the carbon source used in cultivation media, molecular weight of xanthan biosynthesized by isolates from pepper leaves is higher, which indicates better quality of produced biopolymer and potentially wider possibilities of application. The obtained results of xanthan molecular weight were in range from $1 \cdot 10^{5} \mathrm{~g} / \mathrm{moL}$ to $8 \cdot 10^{5} \mathrm{~g} / \mathrm{moL}$, which is similar to the result from literature where average molecular weight of xanthan obtained by $X$. campestris ATCC 33913 was around $5 \cdot 10^{5} \mathrm{~g} / \mathrm{moL}$ (PSOMAS \& al [20]).

This indicates that different Xanthomonas strains may produce macromolecules with different composition, as reported in other study where the polysaccharide produced by the variant (small-colony type) differs adversely in solution properties from that of the parent strain (largecolony type) but also in its lower content of pyruvic acid and 0-acetyl substituents (CADMUS \& al [17]). In some research, viscosity of biopolymer solution is considered as an indicator of xanthan quality (CADMUS \& al [21]). So, GUMUS et al [17] reported in their study that xanthan produced by some strains is exhibited higher viscosity than commercial xanthan and the xanthan obtained by cultivation of some other strains.

Figure 4 shows the results of statistical analysis of the effect of different carbon source on molecular weight of xanthan produced by Xanthomonas strains isolated from crucifers and pepper leaves.
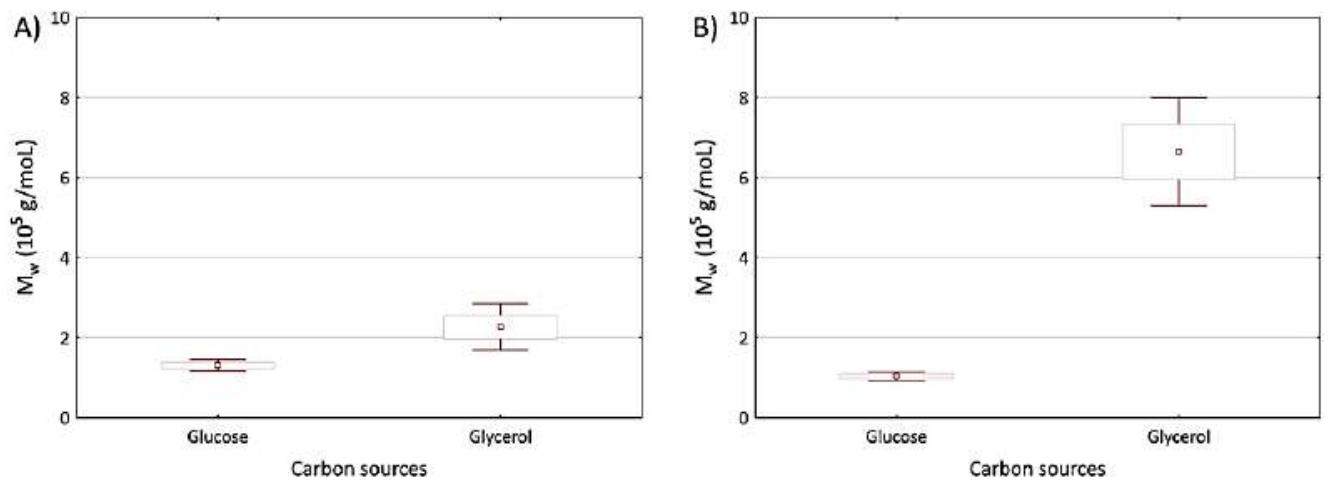

Figure 4. Effect of different carbon sources on molecular weight of xanthan obtained by cultivation of Xanthomonas strains isolated from crucifers (A) and pepper leaves (B).

The results given in Figure 4A and Figure 4B indicate that there is a statistically significant difference in biopolymer quality when glucose and glycerol were used as a carbon source in xanthan production media. According to graphically presented results, xanthan with higher molecular weight was obtained when local wild-type Xanthomonas strains were cultivated on glycerol-based medium. Further, it can be noticed that xanthan produced on glycerol containing medium by pepper leaves' isolates was characterized as the highest quality biopolymer. Literature data is mainly based on the effect of carbon sources on the viscosity of xanthan solutions as an indicator of quality and there are a very small number of researches focused on the effect of carbon sources on the xanthan molecular weight. Results from literature indicate that molecular weight of xanthan obtained by cultivation of $X$. campestris CGMCC 1.1781 strain, obtained from China General Microbiological Culture Collection Center, is greatly affected by xylose and glucose content in cultivation media and that there is a positive correlation between viscosity and xanthan molecular weight (ZHANG \& CHAN [22]).The results obtained in their study suggest that the molecular weight of xanthan derived from media with glucose/xylose mixture were higher than those for xanthan derived from glucose containing medium.

Results discussed above suggest that glycerol, and potentially crude glycerol, are suitable carbon source not only for the xanthan production in large quantities but also 
for the biosynthesis of good-quality biopolymer since the xanthan with the highest molecular weight was obtained by cultivation of both groups of Xanthomonas strains, i.e. strains isolated from crucifers and pepper leaves, on glycerol-based medium. Despite the fact that crude glycerol is an attractive and low cost raw material there is still a need to investigate how all impurities present in crude glycerol affect productivity of Xanthomonas strains and xanthan quality in order to ensure economically justified xanthan production.

\section{Conclusion}

In this research, screening of Xanthomonas strains, isolated from different vegetable cultures with characteristic symptoms of bacteriosis, according to their production of xanthan and its molecular weight on two semi-synthetic media was carried out. The experimental data show that all applied Xanthomonas strains and carbon sources as well as their combination have statistically significant effect on xanthan concentration in cultivation media and molecular weight of produced biopolymer. The Xanthomonas strains isolated from crucifers were more productive on medium with glucose, while the xanthan production by Xanthomonas strains isolated from pepper leaves was more successful using a glycerol-based media. According to the obtained results, glycerol is more suitable carbon source for production of xanthan with the highest molecular weight by all applied Xanthomonas strains. Considering all results discussed above, it can be concluded that Xanthomonas strains isolated from pepper leaves have the greatest potential for application in biotechnological production of xanthan on glycerol-based medium. Results obtained in this research may be a suitable background for future investigations and optimization of the economically justified production of xanthan.

\section{Acknowledgements}

This study is part of the project (451-03-9/202114/200134) funded by the Ministry of Education, Science and Technological Development of the Republic of Serbia.

\section{Conflict of Interest}

The authors has no conflict of interests to declare.

\section{References}

1. F. GARCÍA-OCHOA, V.E. SANTOS, J.A. CASAS, E. GÓMEZ. Xanthan gum: production, recovery, and properties. Biotechnol Adv, 18: 549-579 (2000).

2. A.S. DEMIRCI, I. PALABIYIK, D. APAYDIN, M. MIRIK, T. GUMUS. Xanthan gum biosynthesis using Xanthomonas isolates from waste bread: Process optimization and fermentation kinetics. LWT - Food Sci. Technol, 101: 40-47 (2019).
3. M.B. KASSIM. Production and characterization of the polysaccharide "xanthan gum" by a local isolate of the bacterium Xanthomonas campestris. Afr. J. Biotechnol, 10: 16924-16928 (2011).

4. T. GUMUS, A.S. DEMIRCI, M. MIRIK, M. ARICI, Y. AYSAN. Xanthan gum production of Xanthomonas spp. isolated from different plants. Food Sci Biotechnol, 19: 201-206 (2010).

5. Z.Z. RONČEVIĆ, B.Ž. BAJIĆ, D.G. VUČUROVIĆ, S.N. DODIĆ, J.A. GRAHOVAC, J.M. DODIĆ. Xanthan production on wastewaters from wine industry. Hem. Ind, 71: 145-153 (2017).

6. T. GHASHGHAEI, M.R. SOUDI, S. HOSEINKHANI. Optimization of Xanthan Gum Production from Grape Juice Concentrate Using Plackett-Burman Design and Response Surface Methodology Tahereh. Appl Food Biotechnol, 3: 15-23 (2016).

7. Z. RONČEVIĆ, J. GRAHOVAC, S. DODIĆ, D. VUČUROVIĆ, J. DODIĆ. Utilisation of winery wastewater for xanthan production in stirred tank bioreactor: Bioprocess modelling and optimization. Food Bioprod Process, 117: 113-125 (2019).

8. E.C. REIS, M. ALMEIDA, J.C. CARDOSO, M.A. PEREIRA, C. B.Z. DE OLIVEIRA, E.M. VENCESLAU, J.I. DRUZIAN, R. MARIANO, F. F. PADILHA. Biopolymer synthesized by strains of Xanthomonas sp. isolate from Brazil using biodieselwaste. Macromol Symp, 296: 347-353 (2010).

9. R.A. TRINDADE, A.P. MUNHOZ, C.A.V. BURKET. Raw Glycerol as an Alternative Carbon Source for Cultivation of Exopolysaccharide-Producing Bacteria. $J A B, 3:$ 61-73 (2015).

10. Z. WANG, J. WU, L. ZHU, $X$. ZHAN. Activation of glycerol metabolism in Xanthomonas campestris by adaptive evolution to produce a high-transparency and low-viscosity xanthan gum from glycerol. Bioresour Technol, 211: 390-397 (2016).

11. M. MILAS, M. RINAUDO, B. TINLAND. The viscosity dependence on concentration, molecular weight and shear rate of xanthan solutions. Polym. Bull. 14: 157-164 (1985).

12. S.M. KUMARA, B.A. KHAN, K.C. ROHIT, B. PURUSHOTHAM. Effect of carbon and nitrogen sources on the production of xanthan gum from Xanthomonas campestris isolated from soil. Arch Appl Sci Res, 4:2507-2512 (2012).

13. A.S. MOREIRA, J.L.S. VENDRUSCOLO, C. GILTURNES, C.T. VENDRUSCOLO. Screening among 18 novel strains of Xanthomonas campestris pv pruni. FOOD HYDROCOLLOID, 15: 469-474 (2001).

14. D.J. BRENNER, N.R. KRIEG, J.T. STALEY. Bergy's Manual of Systematic Bacteriology, New York: Springer, 2nd edi., Vol. 2, The Proteobacteria, 63-91 (2005). 
15. B. BAJIĆ, Z. RONČEVIĆ, S. DODIĆ, J. GRAHOVAC, J. DODIĆ. Glycerol as a carbon source for xanthan production by Xanthomonas campestris isolates. Acta Period. Technol, 46: 197-206 (2015).

16. M.C. CADMUS, S.P. ROGOVIN, K.A. BURTON, J.E. PITTSLEY, C.A. KNUTSON, A. JEANES. Colonial variation in Xanthomonas campestris NRRL B-1459 and characterization of the polysaccharide from a variant strain. Can J Microbiol, 22 (7): 942-948 (1976).

17. M. NITSCHKE, V. RODRIGUES. Effect of virulence and serial transfers of Xanthomonas campestris on xanthan gum production. Braz. J. Microbiol, 31: 58-60 (2000).

18. J.K. LEELA, G. SHARMA. Studies on xanthan production from Xanthomonas campestris. Bioprocess Eng, 23: 687-689 (2000).
19. R. NWACHUKWU, A. SHAHBAZI, L. WANG, S. IBRAHIM, M. WORKU, K. SCHIMMEL. Bioconversion of glycerol to ethanol by a mutant Enterobacter aerogenes. AMB Express, 2:20 (2012).

20. S.K. PSOMAS, M. LIAKOPOULOU-KYRIAKIDES, D.A. KYRIAKIDIS. Optimization study of xanthan gum production using response surface methodology. Biochem Eng J, 35: 273-280 (2007).

21. M.C. CADMUS, C.A. KNUTSON, A.A. LAGODA, J.E. PITTSLEY, K.A. BURTON. Synthetic media for production of quality xanthan gum in 20 liter fermenters. Biotechnol Bioeng, 20: 1003-1014 (1978).

22. Z. ZHANG, H. CHEN. Fermentation performance and structure characteristics of xanthan produced by Xanthomonas campestris with a glucose/xylose mixture. Appl Biochem Biotechnol, 160: 1653-1663 (2010). 